\title{
Propriedades Edáficas e Desenvolvimento de Eucalipto em Topossequência na Flona Mário Xavier-RJ
}

\author{
Ranieri Ribeiro Paula ${ }^{1}$, Marcos Gervasio Pereira ${ }^{2}$, \\ Robson Reis Santiago ${ }^{3}$, Hugo Barbosa Amorim ${ }^{4}$ \\ ${ }^{1}$ Departamento de Ciências Florestais, Escola Superior de Agricultura "Luiz de Queiroz", \\ Universidade de São Paulo - ESALQ/USP \\ ${ }^{2}$ Departamento de Solos, Universidade Federal Rural do Rio de Janeiro - UFRRJ \\ ${ }^{3}$ Engenheiro Florestal, ATP Engenharia, Lauro de Freitas, Bahia \\ ${ }^{4}$ Departamento de Silvicultura, Universidade Federal Rural do Rio de Janeiro - UFRRJ
}

\begin{abstract}
RESUMO
O estudo teve como objetivo avaliar a influência de propriedades edáficas na cultura do eucalipto. Foram avaliados, na FLONA Mário Xavier, talhões de Eucalyptus urophilla S. T. Blake aos quatro anos de idade, em uma topossequência: Argissolo Vermelho Amarelo (TS $=$ terço superior); Argissolo Vermelho Amarelo (TM = Terço médio); Planossolo Háplico (TI = terço inferior). Em cada área, foi delimitada uma parcela e avaliados aspectos silviculturais do povoamento, e coletadas amostras de terra para avaliação da fertilidade e da densidade do solo. Não foram verificadas diferenças significativas para as propriedades químicas, somente para densidade do solo, sendo esta maior no TM. Apesar da maior sobrevivência das árvores no TI, em TS e TM foi verificada distribuição diamétrica mais simétrica, com árvores de maior diâmetro e área basal por hectare mais elevada. Os resultados obtidos sugerem a necessidade de manejo diferenciado do povoamento de eucalipto em função das diferenças de relevo, já que estas podem influenciar na idade de corte e no uso final da madeira.
\end{abstract}

Palavras-chave: paisagem, atributos edáficos, manejo florestal.

\section{Edaphic Properties and Eucalyptus Development in Topographic Sequence in 'Mario Xavier' National Forest (Flona), RJ, Brazil}

\begin{abstract}
The purpose of this study was to evaluate the influence of soil properties in the development of eucalyptus plantation. Four-year old stands of Eucalyptus urophylla S. T. BLAKE were evaluated in 'Mario Xavier' National Forest (FLONA) in topographic sequence: two Ultisol areas located in the shoulder (Upper Third) and back slope (Medium Third), and a Planossol area located in the foot slope (Lower Third). For each soil area, a study portion was established and the silvicultural aspects of the stands were evaluated; soil samples were also collected for fertility and bulk density assessment. No significant differences were observed in the chemical properties of the soil, but there were significant differences in bulk density, though, especially in the back slope (MT). Although trees presented longer survival in the foot slope (LT), it was observed that the diameter distribution was more symmetric, with trees of larger diameter and greater basal area per hectare in the shoulder (UT) and back slope (MT). Results obtained suggest the need for differential management of eucalyptus stands due to marked relief differences, once they can influence the age of harvest and final use of wood.
\end{abstract}

Keywords: landscape, edaphic attributes, forest management. 


\section{INTRODUÇÃO}

O gênero Eucalyptus é bastante utilizado em reflorestamentos comerciais em razão de sua elevada taxa de crescimento, plasticidade às diferentes condições de clima e solo, e adequação de sua madeira a diversos usos. O melhoramento genético avançado, bem como as técnicas silviculturais e de manejo desenvolvidas, favorecem seu reflorestamento em diferentes regiões do Brasil. No entanto, condições edáficas locais podem influenciar na dinâmica do povoamento e na tomada de decisão sobre tratos silviculturais e colheita.

A madeira do eucalipto tem sido amplamente utilizada na produção de polpa, papel, carvão para a indústria siderúrgica e painéis reconstituídos, dentre outros usos. A área plantada no País é de 4,259 milhões de hectares, com um crescimento médio anual de $7,4 \%$ no período de 2004 a 2008 (ABRAF, 2009). Nesse contexto, estudos que busquem verificar a influência das propriedades edáficas e ambientais no crescimento do eucalipto assumem destaque, pois serão determinantes para um bom planejamento na implantação e no desenvolvimento dos maciços florestais (Corrêa Neto et al., 2007; Reis et al., 2006; Tonini et al., 2006)

A produtividade dos plantios florestais está relacionada às propriedades do solo que influenciam o suprimento de recursos de crescimento, como a água e os nutrientes, para as árvores, e às propriedades que favorecem o crescimento do sistema radicular (Balieiro et al., 2008; Corrêa Neto et al., 2007; Reis et al., 2006). O crescimento radicular pode ser influenciado por propriedades físicas do solo, como textura, umidade, porosidade e temperatura (Gonçalves \& Mello, 2000).

O conhecimento dos atributos do solo e do relevo auxilia no manejo adequado e pode favorecer o aumento da produtividade (Baptista \& Levien, 2010; Ortiz et al., 2006). O relevo é determinante para a produtividade de plantios florestais, pois imprime condições diferenciadas para a formação do solo e nas condições de drenagem, e influencia a disponibilização de recursos de crescimento para as árvores (Balieiro et al., 2008). Low (1997) verificou que o conteúdo de água e o teor de carbono orgânico no solo foram as variáveis que melhor se correlacionaram com a produtividade do E. grandis, aos 20 anos, na África do Sul. Corroborando essa afirmativa, Corrêa Neto et al. (2007) observaram para E. urophilla, aos dois anos de idade, maior área basal e árvores de maiores diâmetros no terço inferior de uma encosta, onde o solo teria maior quantidade de água disponível, em função da maior proximidade do lençol freático com a superfície.

No Brasil, variáveis climatológicas têm determinado a escolha de espécies de eucalipto (Corrêa Neto et al., 2007). Entretanto, variações locais do relevo podem proporcionar respostas diferentes entre materiais genéticos, em decorrência da interação do genótipo com o ambiente; dessa forma, a escolha de espécies potencialmente aptas deve ser baseada em variáveis tanto climáticas como em outras variáveis ambientais (Barros \& Novais, 1990). Tonini et al. (2006)verificaram que diferentes padrões de crescimento em altura dominante de três materiais genéticos de E. saligna Smith, aos três anos de idade, estavam relacionados com os tipos de solos analisados, indicando, assim, a importância da interação do genótipo com o ambiente.

O presente trabalho teve como objetivo avaliar a influência da fertilidade e da densidade do solo no desenvolvimento de Eucalyptus urophilla S.T. Blake aos quatro anos após plantio, em topossequência na Floresta Nacional (FLONA) Mário Xavier, em Seropédica-RJ.

\section{MATERIAL E MÉTODOS}

\section{1. Área de estudo}

O estudo foi realizado na área da FLONA Mário Xavier, localizada no município de Seropédica-RJ. O clima da região caracteriza-se como Aw - tropical chuvoso, com inverno seco, segundo a classificação de Köppen. A precipitação média anual é de $1.212,7 \mathrm{~mm}$. Os meses de maior pluviosidade são dezembro e janeiro, com média de 182,7 e 194,0 mm, respectivamente. As menores taxas de precipitação são verificadas nos meses de junho, com média de $34,5 \mathrm{~mm}$, e julho, com média de $28,4 \mathrm{~mm}$. A temperatura média anual é de $23,5{ }^{\circ} \mathrm{C}$, sendo a média de fevereiro $\left(26,8^{\circ} \mathrm{C}\right)$ a mais elevada durante o ano e a de julho $\left(20,5^{\circ} \mathrm{C}\right)$, a mais baixa. $\mathrm{Na}$ área, 
são verificados como principais ordens de solos os Argissolos Vermelho Amarelos e os Planossolos Háplicos.

\section{2. Área de amostragem}

A área de estudo constituiu-se de um povoamento de E. urophilla com quatro anos de idade. Foram demarcadas três parcelas, localizadas em posições distintas de uma encosta, sendo: terços superior, médio e inferior. Nesses sítios, foram identificadas as seguintes ordens de solo: Argissolos Vermelho Amarelos, nos terços superior (Ts) e médio (Tm), e Planossolo Háplico no terço inferior (TI) da encosta. As parcelas localizadas nos terços inferior e médio da encosta possuíam área de 1,0 ha; já a parcela instalada no terço superior de encosta apresentava dimensão de 0,49 ha, em função da elevada declividade.

\subsection{Coleta de dados}

Para a avaliação da densidade do solo (Ds), foram coletadas cinco amostras indeformadas nas profundidades de $0-20 \mathrm{~cm}$, com auxílio do anel de Kopecky. Para a caracterização da fertilidade em cada parcela, foram coletadas, entre as linhas de plantio do eucalipto, cinco amostras compostas de solo - formadas a partir de dez amostras simples - nas profundidades de 0-10, 10-20 e 20$40 \mathrm{~cm}$. A amostragem foi realizada entre as linhas da cultura. Posteriormente, as amostras foram conduzidas ao laboratório, sendo peneiradas e destorroadas, obtendo-se assim a Terra Fina Seca ao Ar (TFSA). Desse material, foram determinados os valores de $\mathrm{pH}$ em água, os teores de alumínio (Al), fósforo $(\mathrm{P})$, potássio $(\mathrm{K})$, cálcio $(\mathrm{Ca})$, magnésio $(\mathrm{Mg})$ e carbono orgânico (COT), segundo os métodos preconizados pela Embrapa (1997). Optou-se pela coleta até a profundidade de $40 \mathrm{~cm}$ para avaliação da fertilidade e até $20 \mathrm{~cm}$, para densidade do solo, em razão de a maior concentração de raízes finas ocorrer nessa profundidade (Witschoreck et al., 2003).

Foi registrado, em cada parcela, o diâmetro na altura do peito (DAP) de todas as árvores vivas, e determinado o percentual de falhas, árvores mortas e dominadas. A partir dos diâmetros coletados, foi realizada a distribuição diamétrica das árvores e a área basal por hectare.

\subsection{Análise dos dados}

Os resultados obtidos para as propriedades edáficas foram submetidos à análise de variância, após terem sido atendidos os requisitos de normalidade (Teste de Lilliefors) e homogeneidade das variâncias dos erros (Teste de Cochran e Barttlet). Os valores médios foram comparados entre si pelo Teste de Tukey a $5 \%$ de probabilidade, sendo as análises realizadas no programa estatístico SAEG 9.1.

\section{RESULTADOS E DISCUSSÃO}

Verificou-se maior valor médio $(p<0,05)$ para densidade do solo no TM $\left(1,72 \mathrm{Mg} \mathrm{m}^{-3}\right)$ e menores valores no TI e TS, com 1,42 e 1,43 $\mathrm{Mg} \mathrm{m}^{-3}$, respectivamente (Figura 1). No TM, o processo erosivo certamente favoreceu uma maior remoção do material do horizonte superficial, fazendo com que este apresentasse menor espessura; tal fato refletiu nos maiores valores da densidade do solo na camada 0-20 cm. Como características gerais, os Argissolos Vermelho Amarelos localizados no TS e TM possuem maior teor de argila em profundidade, em função dos mecanismos de translocação de argila, bem como

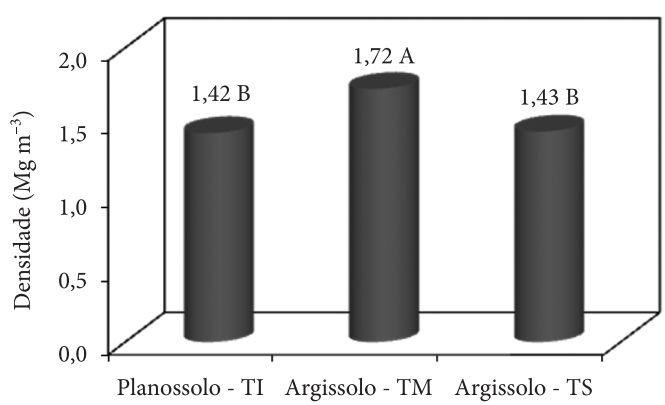

Figura 1. Valores médios de densidade do solo em uma topossequência com E. urophylla aos quatro anos após plantio, na FLONA Mário Xavier, Seropédica-RJ. $\mathrm{TI}=$ Terço inferior; $\mathrm{TM}=$ Terço médio; $\mathrm{TS}=$ Terço superior. Valores médios de cinco repetições. Letras diferentes entre áreas indicam diferenças estatísticas pelo teste de Tukey a $5 \%$ de probabilidade.

Figure 1. Mean values of soil density in a toposequence with E. urophylla at 4 years after planting ,on FLONA Mário Xavier, Seropédica, RJ, Brazil. Where: $\mathrm{TI}=$ Footslope; $\mathrm{TM}=$ Backslope $; \mathrm{TS}=$ Shoulder . Average values of five repetitions. Different letters indicate statistical differences between areas by the Tukey test at $5 \%$ probability. 
das perdas por erosão, que ocorrem nas camadas superficiais. Em relação ao Planossolo Háplico, esse solo é formado por sedimentos coluviais e apresenta drenagem imperfeita, com horizonte $B$ plânico de textura média e os horizontes A e E, com textura arenosa. A maior proximidade do lençol freático com a superfície, associada à drenagem imperfeita do perfil, faz com que, nos períodos de maior precipitação pluviométrica, ocorra a deficiência de oxigênio, o que pode afetar o desenvolvimento do eucalipto.

Não foram constatadas diferenças significativas $(\mathrm{p}<0,05)$ entre as áreas para fertilidade do solo (Tabela 1). Os valores de $\mathrm{pH}$ apresentaram-se em torno de 5,5, porém, a cultura do eucalipto é tolerante à acidez do solo (Barros \& Novais, 1990) e, dessa forma, os valores de $\mathrm{pH}$ observados provavelmente não estão contribuindo de maneira desfavorável para o estabelecimento do eucalipto. Os valores de Al foram baixos $\left(<0,5 \mathrm{cmolc} \mathrm{kg}^{-1}\right.$ TFSA) e podem ser um reflexo da aplicação de calagem na área. Observa-se uma tendência de elevação do $\mathrm{Al} \mathrm{em}$ profundidade, porém, esses valores $\left(>0,4 \mathrm{cmolc} \mathrm{kg}{ }^{-1}\right.$ TFSA) não são prejudiciais ao eucalipto (Barros \& Novais, 1990).

Apesar de não ter sido verificada diferença significativa, existe uma tendência de maiores valores de fertilidade em TI, destacando-se os teores de Ca, K, P e COT nas camadas de 0-10 e 10-20 cm. Corrêa Neto et al. (2007) verificaram, em uma topossequência no campus da Universidade Federal Rural do Rio de Janeiro, diferenças significativas entre três sítios (terço superior "TS", terço médio "TM" e terço inferior "TI" de uma encosta), nas profundidades de $0-20$ e de $20-40 \mathrm{~cm}$. No referido estudo, foi constatado que o terço superior apresentou maiores teores de $\mathrm{Ca}, \mathrm{Mg}$ e $\mathrm{K}$, e menores de $\mathrm{Al}$ em comparação ao terço inferior, nas amostragens entre plantas e entre linhas. É provável que no Planossolo haja menor capacidade de retenção de cátions por causa da textura arenosa encontrada na camada superficial. No presente estudo, essas diferenças não foram encontradas, o que indica que outros fatores estariam corroborando para o desenvolvimento diferenciado do eucalipto nesse ambiente, pois, com exceção dos teores de $\mathrm{P}$, todos os nutrientes apresentam-se em teores adequados para a cultura. A acidez do solo poderia influenciar a disponibilidade de P para as plantas, sendo observados neste estudo valores de $\mathrm{pH}$ e $\mathrm{Al}$ semelhantes entre os sítios, os quais não alteraram a disponibilidade de $\mathrm{P}$ no solo (Tabela 1).

Corrêa Neto et al. (2007) observaram maiores teores de P no TS e no TI em comparação ao TM, estando esses maiores valores relacionados com o incremento em volume. Para E. saligna, dentre

Tabela 1. Propriedades químicas do solo de uma topossequência com plantios de E. urophilla aos quatro anos após plantio, na flona Mario Xavier, SeropédicaRJ.

Table 1. Soil chemical properties of a toposequence with plantings of E. urophylla at 4 years after planting, on FLONA Mário Xavier, Seropédica, RJ, Brazil.

\begin{tabular}{|c|c|c|c|}
\hline \multirow{2}{*}{$\begin{array}{l}\text { Profundidade } \\
(\mathrm{cm})\end{array}$} & \multicolumn{3}{|c|}{$\begin{array}{l}\text { Sítios em estudo/ } \\
\text { Propriedades químicas }\end{array}$} \\
\hline & $\begin{array}{c}\text { Planossolo } \\
\text { (TI) }\end{array}$ & $\begin{array}{l}\text { Argissolo } \\
\text { (TM) }\end{array}$ & $\begin{array}{l}\text { Argissolo } \\
\text { (TS) }\end{array}$ \\
\hline & \multicolumn{3}{|c|}{$\mathrm{pH}$} \\
\hline $0-10$ & $5,1^{\mathrm{A}}$ & $5,5^{\mathrm{A}}$ & $5,5^{\mathrm{A}}$ \\
\hline $10-20$ & $5,5^{\mathrm{A}}$ & $5,9^{\mathrm{A}}$ & $5,7^{\mathrm{A}}$ \\
\hline \multirow[t]{2}{*}{$20-40$} & $5,1^{\mathrm{A}}$ & $5,7^{\mathrm{A}}$ & $5,3^{\mathrm{A}}$ \\
\hline & \multicolumn{3}{|c|}{$\mathrm{Al}\left(\mathrm{cmol} \mathrm{kg}^{-1}\right)$} \\
\hline $0-10$ & $0,1^{\mathrm{A}}$ & $0,2^{\mathrm{A}}$ & $0,2^{\mathrm{A}}$ \\
\hline $10-20$ & $0,1^{\mathrm{A}}$ & $0,1^{\mathrm{A}}$ & $0,0^{\mathrm{A}}$ \\
\hline \multirow[t]{2}{*}{$20-40$} & $0,5^{\mathrm{A}}$ & $0,4^{\mathrm{A}}$ & $0,4^{\mathrm{A}}$ \\
\hline & \multicolumn{3}{|c|}{$\mathrm{P}\left(\mathrm{mg} \mathrm{kg}^{-1}\right)$} \\
\hline $0-10$ & $3,2^{\mathrm{A}}$ & $3,1^{\mathrm{A}}$ & $3,2^{\mathrm{A}}$ \\
\hline $10-20$ & $5,3^{\mathrm{A}}$ & $3,8^{\mathrm{A}}$ & $3,6^{\mathrm{A}}$ \\
\hline \multirow[t]{2}{*}{$20-40$} & $4,6^{\mathrm{A}}$ & $4,9^{\mathrm{A}}$ & $4,2^{\mathrm{A}}$ \\
\hline & \multicolumn{3}{|c|}{$\mathrm{K}\left(\mathrm{cmol}_{\mathrm{c}} \mathrm{kg}^{-1}\right)$} \\
\hline $0-10$ & $0,6^{\mathrm{A}}$ & $0,5^{\mathrm{A}}$ & $0,3^{\mathrm{A}}$ \\
\hline $10-20$ & $0,5^{\mathrm{A}}$ & $0,4^{\mathrm{A}}$ & $0,6^{\mathrm{A}}$ \\
\hline \multirow[t]{2}{*}{$20-40$} & $0,6^{\mathrm{A}}$ & $0,7^{\mathrm{A}}$ & $0,6^{\mathrm{A}}$ \\
\hline & \multicolumn{3}{|c|}{$\mathrm{Ca}\left(\mathrm{cmol}_{\mathrm{c}} \mathrm{kg}^{-1}\right)$} \\
\hline $0-10$ & $1,2^{\mathrm{A}}$ & $1,3^{\mathrm{A}}$ & $0,9^{\mathrm{A}}$ \\
\hline $10-20$ & $1,7^{\mathrm{A}}$ & $1,2^{\mathrm{A}}$ & $1,0^{\mathrm{A}}$ \\
\hline \multirow[t]{2}{*}{$20-40$} & $1,0^{\mathrm{A}}$ & $1,0^{\mathrm{A}}$ & $1,0^{\mathrm{A}}$ \\
\hline & \multicolumn{3}{|c|}{$\mathrm{Mg}\left(\mathrm{cmol}_{\mathrm{c}} \mathrm{kg}^{-1}\right)$} \\
\hline $0-10$ & $1,2^{\mathrm{A}}$ & $1,3^{\mathrm{A}}$ & $0,9^{\mathrm{A}}$ \\
\hline $10-20$ & $1,7^{\mathrm{A}}$ & $1,2^{\mathrm{A}}$ & $1,0^{\mathrm{A}}$ \\
\hline \multirow[t]{2}{*}{$20-40$} & $1,0^{\mathrm{A}}$ & $1,0^{\mathrm{A}}$ & $1,0^{\mathrm{A}}$ \\
\hline & \multicolumn{3}{|c|}{$\operatorname{COT}\left(\mathrm{g} \mathrm{kg}^{-1}\right)$} \\
\hline $0-10$ & $17,0^{\mathrm{A}}$ & $16,0^{\mathrm{A}}$ & $14,0^{\mathrm{A}}$ \\
\hline $10-20$ & $17,0^{\mathrm{A}}$ & $19,0^{\mathrm{A}}$ & $15,0^{\mathrm{A}}$ \\
\hline $20-40$ & $15,0^{\mathrm{A}}$ & $15,0^{\mathrm{A}}$ & $14,0^{\mathrm{A}}$ \\
\hline
\end{tabular}

* Médias de cinco repetições. Letras iguais na mesma linha não diferem estatisticamente pelo teste de Tukey a $5 \%$ de probabilidade. 
a aplicação de N, P, K e calcário dolomítico, o P foi o elemento que proporcionou maior produção volumétrica de madeira aos cinco anos de idade (Mello et al., 1970). Embora no presente estudo não tenha sido observada diferença quanto aos teores de $\mathrm{P}$ entre as áreas, verificou-se maior área basal do eucalipto no TM da encosta (Figura 2), sendo que os teores de P no solo no TM tendem a ser menores que os do TI.

Maiores quantidades de silte e argila favorecem a retenção de água e nutrientes pelo solo, e a elevação dos teores de areia grossa em profundidade pode influenciar na menor retenção de água e nutrientes, prejudicando a produtividade do eucalipto (Correa et al., 1996). No presente estudo, o efeito dessas maiores quantidades de silte e argila parece ser benéfico, pois as árvores de eucalipto localizadas no TM apresentaram maiores valores de área basal, seguidas pelo TS.

As características químicas das duas ordens de solos, a princípio, não estariam diferenciando os sítios quanto ao desenvolvimento do E. urophilla. (Correa et al. 1996) também não verificaram efeitos diretos da fertilidade do solo na produtividade do eucalipto. Porém, supõe-se, neste estudo, que os atributos que poderiam estar influenciando no desenvolvimento da cultura seriam aqueles relacionados à disponibilidade de água, com destaque para a posição topográfica, a textura e a densidade

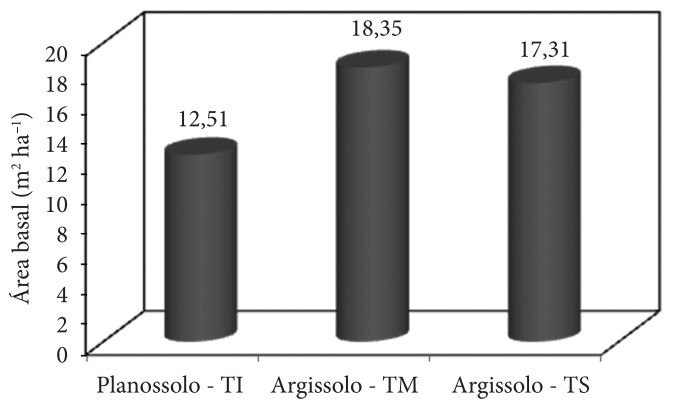

Figura 2. Área basal $\left(\mathrm{m}^{2} \mathrm{ha}^{-1}\right)$ em três sítios de uma topossequência com E. urophylla aos quatro anos após plantio, na FLONA Mário Xavier, Seropédica-RJ. $\mathrm{TI}=$ Terço inferior; TM = Terço médio; TS = Terço superior.

Figure 2. Basal area $\left(\mathrm{m}^{2} \mathrm{ha}^{-1}\right)$ at three sites in a toposequence with $E$. urophylla at 4 years after planting, on FLONA Mário Xavier, Seropédica, RJ, Brazil. Where: $\mathrm{TI}=$ Footslope; $\mathrm{TM}=$ Backslope TS = Shoulder . do solo, sendo o mesmo relatado por Balieiro et al. (2008). Esses fatores poderiam proporcionar condições diferenciadas para o desenvolvimento do eucalipto, influenciando, por exemplo, na relação raiz/parte área. Essa relação pode aumentar em função da elevação da deficiência hídrica, conforme verificado em E. nitens e E. globulus (Moroni et al., 2003). Reis et al. (1985) observaram, para E. grandis, numa sequência de idades, um acúmulo de biomassa radicular duas vezes maior num sítio com solo pouco fértil e maior deficiência hídrica, em comparação com um sítio de melhor qualidade.

É provável que no TI haja maior disponibilidade de água no solo, o que pode favorecer o crescimento do eucalipto. Balieiro et al. (2008) observaram menor crescimento em altura e diâmetro do E. urophylla em Argissolo Vermelho Amarelo no terço superior de uma encosta em comparação ao terço inferior, onde ocorria um Planossolo Háplico, e constataram também maior disponibilidade de água no solo neste último. Reis et al. (2006) verificaram que o aumento da disponibilidade de água no solo, por meio de irrigação, resultou em maior crescimento em diâmetro e volume, aos 38 meses após plantio, de cinco clones de eucalipto (híbridos de E. grandis $\times E$. urophylla e de E. camaldulensis $\times$ Eucalyptus spp.), em comparação com tratamento não irrigado. Contudo, no presente estudo, menores valores para área basal (Figura 4) e árvores de menor diâmetro (Figura 3) foram verificados no TI, indicando que, nesse solo, outros fatores poderiam estar influenciando no desenvolvimento do eucalipto.

As classes de diâmetro onde se concentram os maiores números de indivíduos foram: 11-13 e 13-15 cm, para TI, TM e TS, respectivamente.

O maior percentual de falhas ocorreu no TS $(18,63 \%)$, enquanto que, para os percentuais de árvores mortas e dominadas, os maiores valores foram observados em TM e TS, respectivamente. Maiores sobrevivências foram verificadas em TI seguidas pelo TM (Figura 4). A sobrevivência das árvores é um parâmetro importante na avaliação da adaptação de materiais genéticos aos diferentes sítios (Coutinho et al., 2004; Mendonça et al., 2008). Com o decorrer do tempo, um maior número de árvores competindo por recursos ou mesmo sobre condições limitantes de crescimento poderá 


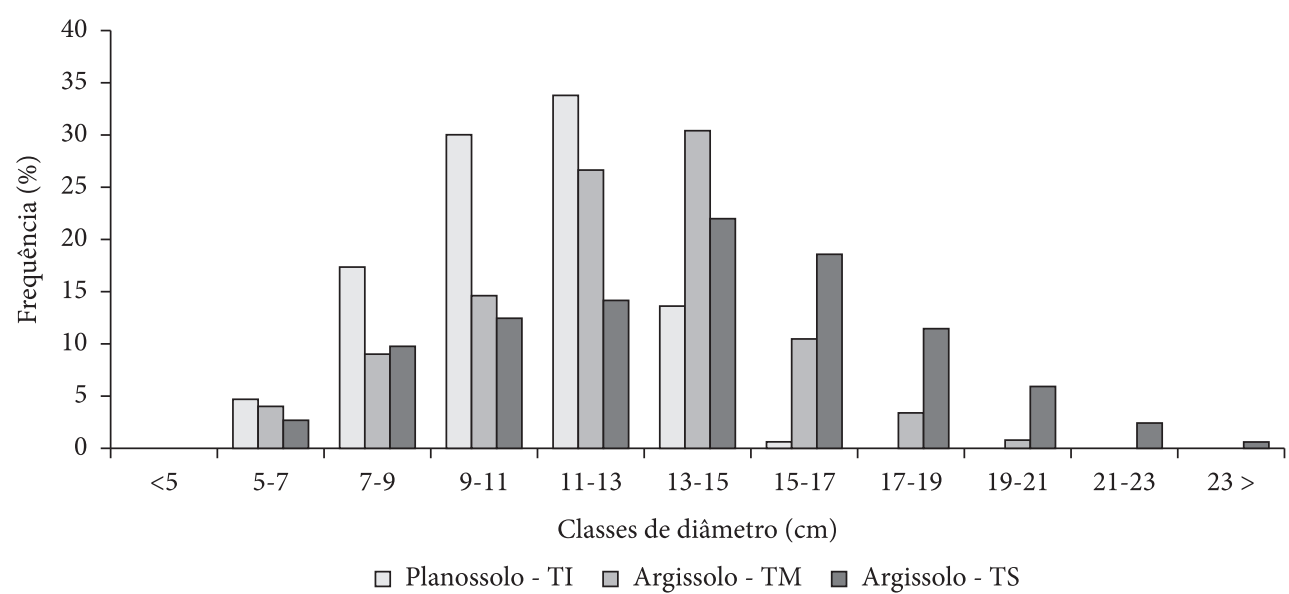

Figura 3. Frequência por classe de diâmetro em uma topossequência com E. urophylla aos quatro anos após plantio, na FLONA Mário Xavier, Seropédica-RJ. TI = Terço inferior; TM = Terço médio; TS = Terço superior.

Figure 3. Frequency per diameter class in a toposequence with E. urophylla at 4 years after planting,on FLONA Mário Xavier, Seropédica, RJ, Brazil.Where:TI - Footslope; TM - Backslope; TS - Shoulder.

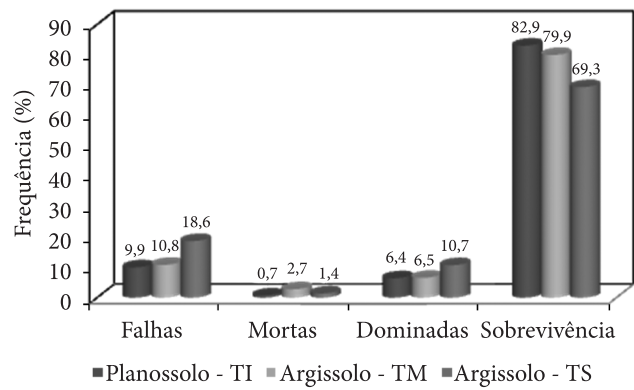

Figura 4. Percentuais (\%) de falhas, árvores mortas, árvores dominadas e sobrevivência, por sítio, em uma topossequência com E. urophylla aos quatro anos após plantio, na FLONA Mário Xavier, Seropédica-RJ. $\mathrm{TI}=$ Terço inferior; $\mathrm{TM}=$ Terço médio; $\mathrm{TS}=$ Terço superior.

Figure 4. Percentages (\%) of failures, dead trees, dominated trees and survival by site in a toposequence with E. urophylla at 4 years after planting, on FLONA Mario Xavier, Seropédica, RJ, Brazil. Where: $\mathrm{TI}=$ Footslope; $\mathrm{TM}=$ Backslope TS = Shoulder.

influenciar na sobrevivência e na distribuição dos diâmetros, favorecendo a presença de árvores de menores diâmetros (Figura 3). Corrêa Neto et al. (2007) verificaram maior número de árvores vivas nas parcelas experimentais localizadas no TM e, no TI, maior número de falhas em comparação ao TS. Porém, a maior área basal foi observada no TI, com 4,64 $\mathrm{m}^{2} \mathrm{ha}^{-1}$, seguido pelo TS, com 4,11 $\mathrm{m}^{2} \mathrm{ha}^{-1}$, sendo para o TM encontrado ainda valor bem abaixo $\left(2,81 \mathrm{~m}^{2} \mathrm{ha}^{-1}\right)$, aos dois anos após plantio. Balieiro et al. (2008) encontraram, na mesma área objeto de estudo de Corrêa Neto et al. (2007) 1,5 ano mais tarde, árvores com menores diâmetros e altura no TS, sendo os valores para essas variáveis estatisticamente iguais no TI e no TM da encosta.

Em povoamentos equiâneos, geralmente é observada distribuição diamétrica tendendo à curva normal (Gauss), em que as maiores frequências se concentram próximas à média (Husch et al., 1993). Dessa forma, as mudanças na estrutura diamétrica e na sobrevivência das árvores em cada sítio são um indicativo das diferentes interações do genótipo com o ambiente e devem ser levadas em conta no planejamento de plantio e colheita. Apesar de a maior sobrevivência de plantas ter ocorrido no TI (Figura 4), é provável que essas estejam em condições limitantes de crescimento, associadas às características do solo inerentes a ordem dos Planossolos. Dentre essas características, pode haver algum impedimento ao crescimento radicular ou mesmo o excesso de água nos períodos chuvosos, o que influenciaria na disponibilidade de oxigênio do solo (Gonçalves \& Mello, 2000). Esses fatores podem ter contribuído no menor crescimento radicular, ocasionando árvores de diâmetro reduzido (Figura 3), o que certamente influenciou nos menores valores para área basal no TI (Figura 2).

Os solos, de modo geral, são constituídos por material sólido e por espaços porosos, cujo preenchimento apresenta variáveis proporções de ar e água (Raven et al., 2001). Em condições de 
saturação hídrica, como nas inundações ou nas situações de encharcamento, o oxigênio presente nos espaços entre as partículas do solo é substituído pela água. Dessa maneira, cria-se um ambiente hipóxico ou anóxico para o sistema radicular, uma vez que o oxigênio difunde-se muito lentamente no meio aquoso, com a formação de um ambiente aeróbico de apenas poucos milímetros na superfície aquosa (Lobo \& Joly, 2000; Larcher, 2006). Juntamente com a restrição das trocas gasosas entre o solo e a atmosfera, a saturação hídrica do solo pode alterar sua microbiota e seu $\mathrm{pH}$, além de diminuir as taxas de decomposição da matéria orgânica (Lobo \& Joly, 2000). Dessa forma, supõe-se, neste estudo, que esteja havendo no TI uma maior dificuldade de desenvolvimento radicular, principalmente por causa da deficiência de oxigênio. Costa et al. (2009) constaram alto risco de anoxia em Planossolos no Rio Grande do Sul. Embora o Planossolo possa apresentar algum impedimento físico ao crescimento radicular, acredita-se que este não seria suficientemente restritivo ao eucalipto. Entretanto, o aumento de 0,4 para 4,2 MPa na resistência do solo à penetração foi responsável pela redução $71 \mathrm{e}$ $31 \%$ no comprimento das raízes primárias e laterais de eucalipto, respectivamente (Misra \& Gibbons, 1996). Dessa forma, novos estudos deverão ser feitos para verificar o padrão das raízes do eucalipto, bem como as características físicas do solo, a maiores profundidades, na área do presente estudo.

Apesar de não terem sido observadas diferenças estatísticas entre os atributos químicos, verificouse que a densidade do solo foi maior no TM, onde também foi observada maior área basal. Tal fato leva a supor que, em cada sítio, estaria ocorrendo condições diferenciadas para o crescimento das árvores. No Argissolo Vermelho Amarelo, localizado no TS, é possível que a menor competição ocasionada pela maior mortalidade de plantas tenha favorecido o incremento em diâmetro. Já no TM, apesar de ter sido verificado um menor número de indivíduos com maiores dimensões, o elevado número de indivíduos nas classes centrais - sendo essas superiores àquelas observadas em TI - contribuiu para valores de área basal mais elevada (Figura 2). No TI, embora tenha havido maior sobrevivência das árvores, estas não conseguiram atingir maiores diâmetros até os quatro anos após plantio. Dessa forma, mudanças nos padrões de desenvolvimento em povoamentos implantados em gradientes topográficos podem influenciar na tomada de decisão sobre o plantio, a idade de colheita e o uso final da madeira, e devem ser consideradas no planejamento florestal.

As variações topográficas dentro de um mesmo estrato climático podem levar à formação de padrões de crescimento diferenciados (Spurr \& Barnes, 1980). As variações nos parâmetros dendrométricos, com a posição da encosta e o tipo de solo, demonstram a influência dos atributos edáficos na produtividade do eucalipto. Porém, neste estudo, percebeu-se que, em virtude de não terem sido verificadas diferenças entre as áreas quanto às propriedades químicas e tendo sido apenas observadas diferenças estatísticas entre os valores médios de densidade do solo, os atributos do solo avaliados não interferiram de maneira direta nas diferenças encontradas para a área basal.

\section{CONCLUSÕES}

Os atributos químicos foram estatisticamente iguais entre as áreas e não estariam, a princípio, influenciando no desenvolvimento do eucalipto.

As diferenças na área basal, na distribuição diamétrica e na sobrevivência entre as áreas aos quatro anos após plantio indicam a necessidade de um manejo diferenciado do povoamento quanto à idade de colheita e ao uso final da madeira, e devem ser consideradas em plantios comerciais com a espécie estudada.

\section{STATUS DA SUBMISSÃO}

Recebido: 30/12/2011

Aceito: 06/05/2012

Publicado: 30/09/2012

AUTOR(ES) PARA CORRESPONDÊNCIA

Ranieri Ribeiro Paula

ESALQ/USP, Av. Pádua Dias, 11, CEP 13418-900,

Piracicaba, SP, Brasil.

e-mail:ranieri@usp.br

\section{Marcos Gervasio Pereira}

UFRRJ, BR 465 km 7, CEP 23890-000,

Seropédica, RJ, Brasil.

e-mail: gervasio@ufrrj.br 


\section{REFERENNCIAS}

Associação Brasileira de Produtores de Florestas Plantadas - ABRAF. Anuário estatístico, ano base 2008. Brasília: ABRAF; 2009.

Barros NF, Novais RF. Relação solo-eucalipto. Viçosa: Folha de Viçosa; 1990.

Baptista J, Levien R. Métodos de preparo de solo e sua influência na erosão hídrica e no acúmulo de biomassa da parte aérea de Eucalyptus saligna em um Cambissolo Háplico da depressão central do Rio Grande do Sul. Revista Árvore 2010; 34(4): 567-575. http://dx.doi. org/10.1590/S0100-67622010000400001

Balieiro FC, Oliveira WC, Pereira MG, Anjos LHC, Piccolo MC, Jaccoud CF. Fertilidade e carbono do solo e uso da água pelo eucalipto numa topossequência em Seropédica, RJ. Revista Árvore 2008; 32(1): 153-162.

Corrêa Neto TA, Anjos LHC, Pereira MG, Amorim HB, Jaccoud CFS. Atributos edafoambientais e parâmetros dendrométricos de plantios de eucalipto em uma topossequência no campus da UFRRJ, Seropédica-RJ. Ciência Florestal 2007; 17(1): 43-51.

Correia JR, Costa LM, Neves JC, Cruz CD. Análise de trilha ("Path analysis") no estudo do relacionamento entre características físicas e químicas do solo e a produtividade do eucalipto. Revista Árvore 1996; 20(2): 161-169.

Costa AM, Curi N, Araújo EF, Marques JJ, Menezes MD. Avaliação do risco de anoxia para o cultivo do eucaliptono Rio Grande do Sul utilizando-se levantamento de solos. Scientia Forestalis 2009; 37(84): 367-375.

Coutinho JLB, Santos VF, Ferreira RFC, Nascimento JCB. Avaliação do comportamento de espécies de Eucalyptus spp. na Zona da Mata Pernambucana. I: Resultados do primeiro ano - 2001. Revista Árvore 2004; 28(6): 771-775. http://dx.doi.org/10.1590/S010067622004000600001

Embrapa. Manual de métodos de análise de solo. Rio de Janeiro: Embrapa Solos; 1997.

Husch B, Miller CI, Beers TW. Forest Mensuration. 3rd ed. Malabar: Krieger Publishing Company; 1993.

Larcher W. Ecofisiologia Vegetal. São Paulo: Rima; 2006.

Lobo PC, Joly CA. Aspectos ecofisiológicos da vegetação de mata ciliar do sudeste do Brasil. In: Rodrigues RR, Leitão Filho HF, editores. Matas Ciliares: Conservação e recuperação. São Paulo: EDUSP; 2000.

Low JH. A site-growth study of Eucalyptus grandis in the Mpumalanga Escarpmentarea, Southern African. Forestry Journal 1997; 180: 1-13.
Mello HA, Mascarenhas Sobrinho J, Simões JW, Couto HTZ. Resultados da aplicação de fertilizantes minerais na produção de madeira de Eucalyptus saligna SM. em solos de cerrado do Estado de São Paulo. IPEF / Instituto de Pesquisas e Estudos Florestais 1970; 1: 7-26.

Mendonça AVR, Carneiro JGA, Barroso DG, Santiago AR, Freitas TAS, Souza JS. Desempenho de quatro espécies de Eucalyptus spp em plantios puros e consorciados com sabiá (Mimosa caesalpiniaefolia Benth) em cava de extração de argila. Revista Árvore 2008; 32(3):395-405.

Misra RK, Gibbons AK. Growth and morphology of eucalypt seedling-roots, in relationto soil strength arising from compaction. Plant Soil 1996; 182: 1-11. http://dx.doi.org/10.1007/BF00010990

Moroni MT, Worledge D, Beadle CL. Root distribution of Eucalyptus nitens and E. globulus in irrigated and droughted soil. Forest Ecology and Management 2003; 177(1-3): 399-407. http://dx.doi.org/10.1016/S03781127(02)00410-3

Ortiz JL, Vettorazzi CA, Couto HTZ, Gonçalves JLM. Relações espaciais entre o potencial produtivo de um povoamento de eucalipto e atributos do solo e do relevo. Scientia Forestalis 2006; 72: 67-79.

Gonçalves JLM, Mello SLM. O sistema radicular das árvores. In: Gonçalves JLM, Benedetti V, editores. Nutrição e fertilização florestal. Piracicaba: IPEF; 2000.

Raven PH, Evert RE, Echhorn SE. Biologia Vegetal. 6rd ed. Guanabara Koogan; 2001.

Reis MGF, Kimmins JP, Rezende GC, Barros NF. Acúmulo de biomassa em uma seqüência de idade de Eucalyptus grandis plantado no cerrado em duas áreas com diferentes produtividades. Revista Árvore 1985; 9(2): 149-162.

Reis GG, Reis MGF, Fontan ICI, Monte MC, Oliveira CHR. Crescimento de raízes e da parte aérea de clones de híbridos de Eucalyptus grandis x Eucalyptus urophylla $\mathrm{e}$ de Eucalyptus camaldulensis $\mathrm{x}$ Eucalyptus spp submetidos a dois regimes de irrigação no campo. Revista Árvore 2006; 30(6): 921-931.

SAEG Sistema para Análises Estatísticas. versão 9.1. Viçosa: Fundação Arthur Bernardes; 2007.

Spurr SH, Barnes BV. Forest ecology. New York: JohnWiley; 1980.

Tonini H, Schneider PR, Finger CAG. Curvas de índice de sítio para povoamentos clonais de Eucalyptus saligna Smith para a depressão central e serra do sudeste, Rio Grande do Sul. Ciência Florestal 2006; 16(1): 27-43.

Witschoreck R, Schumacher MV, Caldeira MVW. Estimativa da biomassa e do comprimento de raízes finas em Eucalyptus urophylla S.T. BLAKE no município de Santa Maria - RS. Revista Árvore 2003; 27(2): 177-183. 